\title{
Research Square \\ Predicting C02 Trapping Efficiency In Saline Aquifers By Machine Learning System: Implication To Carbon Sequestration
}

Hung Vo-Thanh ( $\sim$ vothanhhung198090@gmail.com )

Seoul National University https://orcid.org/0000-0002-7094-9380

Kang-Kun Lee

Seoul National University

\section{Research Article}

Keywords: CO2 storage, CCS, Machine Learning, XGboost, Saline aquifers

Posted Date: September 20th, 2021

DOI: https://doi.org/10.21203/rs.3.rs-841564/v1

License: (c) (1) This work is licensed under a Creative Commons Attribution 4.0 International License.

Read Full License 


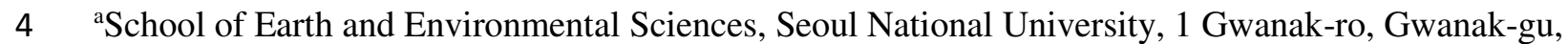

5 Seoul 08826, South Korea

6 * Corresponding author: vothanhhung198090@gmail.com/vothanhhung1990@snu.ac.kr

7 ORCID: 0000-0002-7094-9380

\section{Predicting $\mathrm{CO}_{2}$ trapping efficiency in saline aquifers by machine learning system: Implication to Carbon Sequestration} Hung Vo Thanh*', Kang-Kun Lee

\section{Abstract}

Carbon dioxide $\left(\mathrm{CO}_{2}\right)$ storage in saline formations has been identified as a practical approach to reducing $\mathrm{CO}_{2}$ levels in the atmosphere. The residual and solubility of $\mathrm{CO}_{2}$ in deep saline aquifers are essential mechanisms to enhance security in storing $\mathrm{CO}_{2}$. In this research, $\mathrm{CO}_{2}$ residual and solubility in saline formations have been predicted by adapting three Machine Learning models called Random Forest (RF), extreme gradient boosting (XGboost), and Support Vector Regression (SVR). Consequently, a diversity of the field-scale simulation database including 1509 data samples retrieved from reliable studies, was considered to train and test the proposed models to achieve this task. Graphical and statistical indicators were evaluated and compared the predictive ML model performance. The predicted results denoted that the proposed ML models are ranked from high to low as follows: XGboost $>$ RF $>$ SVR. Additionally, the performance analyses revealed that the XGboost model demonstrates higher accuracy in predicting $\mathrm{CO}_{2}$ trapping efficiency in saline formation than previous ML models. The XGboost model yields very low root mean square error (RMSE) and $\mathrm{R}^{2}$ for both residual and solubility trapping efficiency. At last, the applicable domain of XGboost model was validated, and only 24 suspected data points were recognized from the entire databank.

Keywords: $\mathrm{CO}_{2}$ storage, $\mathrm{CCS}$, Machine Learning, XGboost, Saline aquifers 


\section{Highlights}

$26-\mathrm{CO}_{2}$ solubility and residual trapping is predicted with high accuracy using Machine Learning

27 technique.

28 XGboost exhibits the higher accuracy among developed models

29 - The application domain of XGboost is validated by Williams plot

30

31

32

33

34

35

36

37

38

39

40

41

42

43

44 


\section{Introduction}

46 Global warming is one of the most pressing environmental concerns to alert throughout the world 47 (Abas and Khan, 2014). The massive emission of greenhouse gases (GHG) is related to $\mathrm{CO}_{2}$ 48 sources, which estimates $30 \%$ of the total anthropogenic emission (Schmalensee et al., 1998). $\mathrm{CO}_{2}$ 49 emission in the atmosphere has resulted mainly from the burning of fossil fuels (Boot-Handford et 50 al., 2014). Therefore, it is necessary to find a way to slow down $\mathrm{CO}_{2}$ levels in the atmosphere, and 51 one of the potential solutions is to capture carbon and store $\mathrm{CO}_{2}$ in the subsurface (Dai et al., 2017).

52 This solution is called Carbon Capture and Storage (CCS). CCS can be applied in geological 53 formations, marine sediment, and saline aquifers (Vo Thanh et al., 2020a). Among these storage 54 candidates, the saline aquifers demonstrated as the most potential candidate for CCS solution (Vo 55 Thanh et al., 2019). $\mathrm{CO}_{2}$ storage in deep saline formations could be evaluated by conventional 56 simulation or analytical methods (Aminu et al., 2017; Bachu, 2008; Zapata et al., 2020).

57 Also, $\mathrm{CO}_{2}$ sequestration for field-scale simulation considered many data types such as geological 58 background, petrophysical properties, and reservoir characterization (Song et al., 2020). To 59 forecast storage efficiency and estimate field candidates' feasibility, the field study has been 60 investigated in two approaches. Firstly, the evaluation of reservoir variables in an aquifer is 61 affected by the potential of $\mathrm{CO}_{2}$ storage capacity (Vo Thanh et al., 2020c; Xu et al., 2017). The 62 second approach is emphasized on four trapping types, including structural, residual, solubility, 63 and mineral trappings, to identify risk analysis of interest saline reservoir (Dai et al., 2017, 2016, 64 2014; Vo Thanh et al., 2020a). Furthermore, the geological parameters mainly influence $\mathrm{CO}_{2}$ 65 trapping performance to point out as follows: pay thickness, depth, residual gas saturation, porosity, 66 permeability, salinity formation, heterogeneity (Date, 2014; Issautier et al., 2013; Jia et al., 2018;

67 Kumar et al., 2005; Sarkarfarshi et al., 2014). 
68 Recently, several scholars conducted the compositional reservoir simulation in field-scale model 69 for predicting the effectiveness of $\mathrm{CO}_{2}$ trapping in deep saline aquifers (Baz et al., 2016; Singh et 70 al., 2021; Sohal et al., 2021; Soltanian et al., 2016). The residual and solubility trapping are two 71 crucial factors for security and safety in geological $\mathrm{CO}_{2}$ storage. Thus, to manage the storage of $72 \mathrm{CO}_{2}$ in saline formation, it is mandatory to have reliable prediction residual and solubility trapping 73 efficiency (Dejam and Hassanzadeh, 2018; Long Nghiem et al., 2009; Szulczewski et al., 2012).

74 However, predicting these two trapping efficiency by the field-scale simulation requires a lot of 75 subsurface data. Also, this data is too expensive to acquire all of the necessary information for the 76 simulation model. To address this issue, a new approach needs to be explored for improving the 77 accuracy of predicting trapping efficiency in brine aquifers. In the most recent years, machine 78 learning (ML) techniques are well-known as powerful for solving the complex in the petroleum 79 industry and environmental science (Ahmadi et al., 2016, 2015; Mahdaviara et al., 2021; Vo Thanh 80 et al., 2020d). Also, ML algorithms have successfully developed several high accuracy predictive 81 models in CCS. Amer et al. proposed the intelligence method for predicting $\mathrm{CO}_{2}$ solubility in brine 82 with a high agreement between anticipated results and experimental data (Amar et al., 2019).

83 In the problems of $\mathrm{CO}_{2}$ sequestration in the subsurface, the extreme gradient boost (XGBoost) is 84 developed for estimating the optimal sequestration depth in saline formation (Zhang et al., 2020). 85 Similarity, Support Vector Regression (SVR) was coupled with optimization techniques to assess 86 the permeability changing during $\mathrm{CO}_{2}$ injection in coal seams. Another application of $\mathrm{ML}$ 87 approaches in $\mathrm{CO}_{2}$ enhanced oil recovery and storage by (Chen and Pawar, 2019), these 88 researchers were used Random Forest $(\mathrm{RF})$ and SVR to construct the high accuracy model for 89 estimating oil production and storage performance in residual oil zones of Permian Basin. 90 Nevertheless, these scholars were used the synthetic homogeneous model for the generation of 
large amount of databases for training ML models. Then, the optimal ANN predicted models were used to apply for real field application. Although, the predicted results were achieved between real field and ML models. But the research question needs be to be solved here. Should we use the real

94 field-scale simulation results to generate the more reliable $\mathrm{ML}$ models for predicting $\mathrm{CO}_{2}$ trapping efficiency in saline aquifers? This question is the research gap for our study. Thus, the objective of this paper is to collect the field-scale simulation results around the world available in literature review for developing the robust and accuracy ML models. In this study, several popular ML methods have been developed to assess the residual and solubility of brine aquifers in quick and and graphical visualization are used to rank the best ML model for future employment perspective. In order to explore the stability of employed paradigm, the comparison of best ML model and previous study was proceeded by analyzing the statistical indicators and fitting curves. Lastly, the Williams plot was used for determining the applicable domain of the best ML model. The problem of this research illustrates in Figure 1. This figure illustrate the sketch for the proposing research. The robustness of developing ML models would be compared with the existing study that considered only single reservoir for their research. In real application, the diversity of reservoirs is main challenge for predicting $\mathrm{CO}_{2}$ trapping performance. Thus, this drawback will be solved in this research by considering dffirent reservoir models into one ML models for demonstration the robustness as well as the applicable of our ML models. To the best of our knowdege, this study is first attempt to consider muttiple simulation field data 112 around the world for developing the $\mathrm{ML}$ based $\mathrm{CO}_{2}$ storage capacity. This work provide the useful 113 for reservoir engineer to monitor and evaluation CO2 storage in the early phase of CCS project. 
114 Utimately, the proposing method in this paper could be adapted for related studies because it is 115 easy to conduct and reproduce in ML applicatipns.

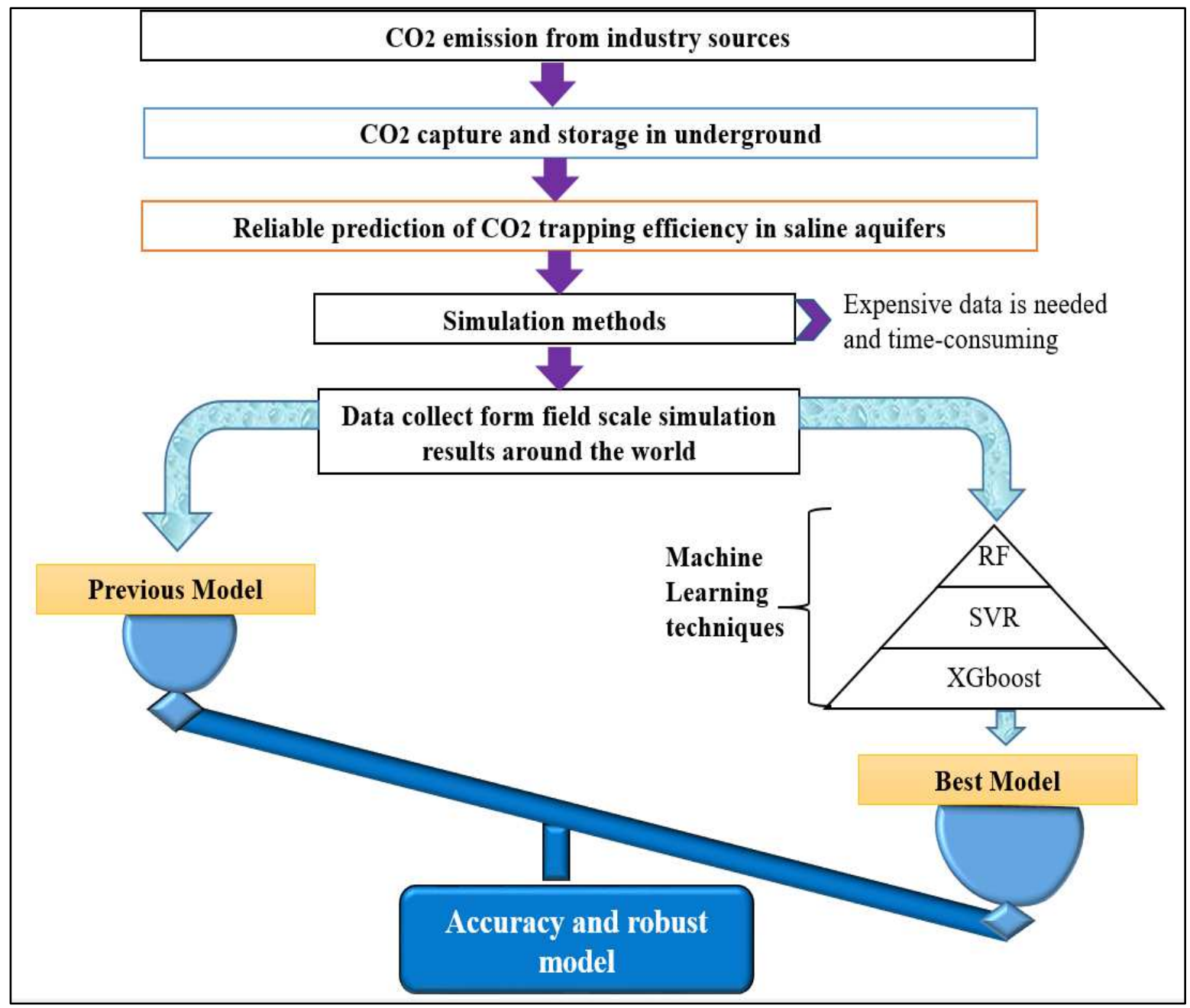

118 Figure 1. This schematic shows the illustration of the research question

2. Methodology

121 This section starts with data collection and description, followed by the theory of the ML

122 algorithms applied in this paper, and finishes with a workflow to develop the ML model. 
124 The first step of developing any machine learning model is gathering the datasets. Here we 125 collected 1509 simulation samples from reliable published literature (Ajayi et al., 2019; Al126 khdheeawi et al., 2018; Al-Khdheeawi et al., 2018b, 2018a, 2018c; Anchliya et al., 2012; 127 Foroozesh et al., 2018; Hsieh et al., 2013; Jin et al., 2012; Jun et al., 2019; Khudaida and Das, 2020; Kim et al., 2019; Kumar et al., 2005; Lee et al., 2010; Li et al., 2020; Liner et al., 2011; Liu 129 et al., 2020; Mohajeri and Shariatipour, 2019; L Nghiem et al., 2009; Noushabadi et al., 2018; 130 Pham et al., 2013; Sifuentes et al., 2009; Song et al., 2020; Sung et al., 2014; Vo Thanh et al., 131 2020b; Xiao et al., 2019; Zapata et al., 2020). The study area of collected data was conducted 132 around the world, including Sleipner (Norway), Shenhua (China), Taiwan, Cuu Long Basin 133 (Vietnam), Gorge V (Korea), Kansas (USA), Ketzin (Germany), Abu Dhabi, Israel, and UK. Also, 134 the reservoir simulation results were produced from CMG-GEM, ECLIPSE, TOUGH2, STAR, and STOM-CO2. Figure 2 displays the location study of simulation results to gather for ML study.

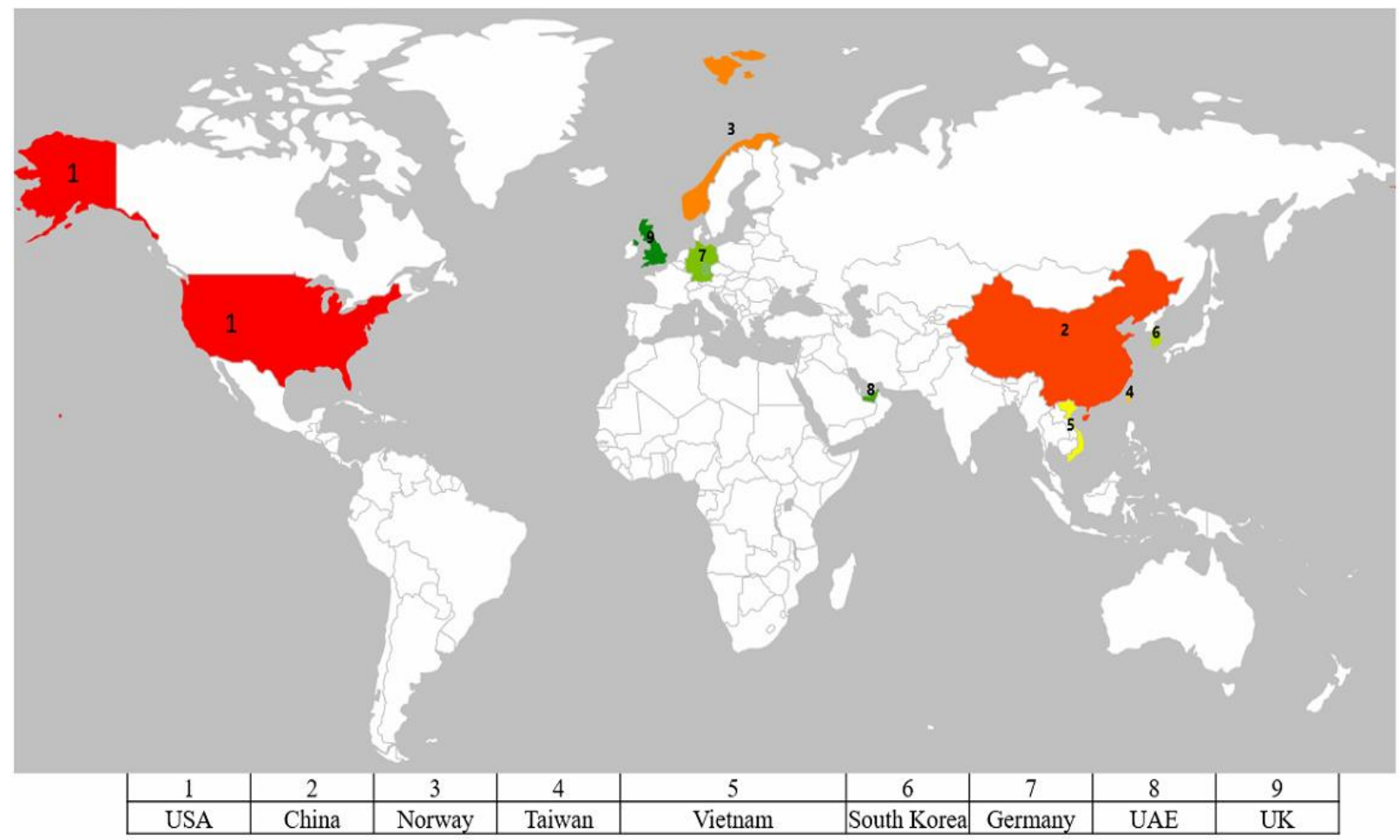


138 The diversity of characteristics of storage formations and simulation packages was expected to 139 construct the powerful ML models for predicting $\mathrm{CO}_{2}$ trapping efficiency in saline formations 140 accurately. The calculation of trapping efficiency is determined by the following equation (Long 141 Nghiem et al., 2009):

142 Residual Trapping Index $(\mathrm{RTI})=\frac{\text { Total mass of } \mathrm{CO}_{2} \text { trapped as residual }(\mathrm{kg})}{\text { Total mass of } \mathrm{CO}_{2} \text { injected }(\mathrm{kg})}$

143 Solubility Trapping Index $(\mathrm{STI})=\frac{\text { Total mass of } \mathrm{CO}_{2} \text { dissolved in brine }(\mathrm{kg})}{\text { Total mass of } \mathrm{CO}_{2} \text { injected }(\mathrm{kg})}$

144 The geological factors and injection parameters were considered as input variables for construction 145 machine learning (ML) models, while the residual trapping index (RTI) and solubility trapping 146 index (STI) were defined as output. Table 1 summarizes the statistical parameters and the detailed 147 description of input and output for employed databases. The injection time, post-injection period, 148 porosity, permeability, thickness, Salinity, depth, residual gas saturation, pressure, temperature, 149 and injection rate are determined as the input features for developing ML model, and the outputs 150 consider the RTI and STI. These output was extracted from published literature using grabit tool 151 matlab (https://www.mathworks.com/matlabcentral/fileexchange/7173-grabit). 
Table 1. The description of inputs and outputs for ML models

\begin{tabular}{|c|c|c|c|c|c|}
\hline & & Min & Mean & Max & $\begin{array}{c}\text { Standard } \\
\text { Deviation }\end{array}$ \\
\hline \multirow[b]{2}{*}{ Outputs } & RTI & 0.0163 & 0.36805 & 0.98332 & 0.2323 \\
\hline & STI & 0.00036 & 0.27481 & 0.89298 & 0.167286 \\
\hline & Injection period (years) & 3.8 & 33.6952 & 100 & 24.39096 \\
\hline & Post injection period (years) & 7.65549 & 917.237 & 7988.31 & 1530.578103 \\
\hline & Min_Porosity & 0 & 0.08848 & 0.3 & 0.102693 \\
\hline & Max_Porosity & 0.093 & 0.26138 & 0.47 & 0.095946 \\
\hline & Min_Permeability (mD) & 0.0001 & 26.4085 & 1743 & 199.099069 \\
\hline & Max_Permeability(mD) & 5.615 & 437.368 & 2029 & 455.445925 \\
\hline & Thickness (m) & 5 & 244.48 & 1500 & 170.53674 \\
\hline & Salinity (ppm) & 10000 & 97226.4 & 320000 & 79871.2278 \\
\hline & Min_Depth (m) & 560.83 & 1464.49 & 3650 & 903.183053 \\
\hline & Max_Depth (m) & 704.69 & 1725.75 & 3853 & 914.910919 \\
\hline & Residual gas saturation & 0 & 0.19911 & 0.5 & 0.156826 \\
\hline & Temperature $\left({ }^{\circ} \mathrm{C}\right)$ & 30 & 53.9876 & 103 & 21.257944 \\
\hline & Pressure $(\mathrm{MPa})$ & 7.5 & 18.3503 & 50 & 11.075672 \\
\hline Inputs & Injection rate (ton/day) & 3.47 & 2582.95 & 65753 & 7483.057286 \\
\hline
\end{tabular}

\subsection{Machine Learning algorithms}

159 In this study, we develop the predictive model for prediction residual and solubility trapping in 160 saline formations. Three powerful machine learning including Support Vector Regression (SVR),

161 Random Forest (RF), and Extremely Gradient Boosting (XGBoost) was used to construct the 162 intelligent prediction model. The following subsections describe the theory of these machine 163 learning methods. 


\subsubsection{Support Vector Regression (SVR)}

167

168

169

170

171

172

173

174

175

176

177

178

179

180

181

182

183

184

185

186

187

188

The Support Vector Regression (SVR) is the regression method that has been employed in many research themes (Chen and Pawar, 2019). The basic function of support vector regression can be described as following (Vapnik, 2013):

$$
g(\boldsymbol{x})=\omega^{T} \phi(x)+a
$$

where, $\phi$ illustrate for mapping function, $w$ is a weight factor, $x$ and $a$ represent for input vector and bias. The popular regression version of SVM, $\varepsilon$-SVR, was adapted in this study. By using the $N_{\mathrm{s}}$ training samples, the standard formula for $\varepsilon$-SVR is written by (Vapnik, 2013):

$$
\min _{\omega, b, \xi, \xi^{*}} \frac{1}{2} \omega^{T} \omega+C \sum_{i=1}^{N_{S}}\left(\xi_{i}+\xi_{i}^{*}\right)
$$

Subject to $\omega^{T} \phi\left(x_{i}\right)+b-y_{i} \leq \varepsilon+\xi_{i}$,

$$
y_{i}-\omega^{T} \phi\left(x_{i}\right)-b \leq \varepsilon+\xi_{i}^{*},
$$

$$
\xi_{i}, \xi_{i}^{*} \geq 0, i=1,2, \ldots, N_{s}
$$

where, $C$ stands for the penalty parameter, and $\xi_{\mathrm{i}}$ and $\xi_{\mathrm{i}}^{*}$ are the slack parameters that state the minimum and maximum range training errors pointing to an error tolerance $\varepsilon$ (Chen and Pawar, 2019). In this study, the radial basis function (rbf) kernel is used for training the SVR model. The equation of rbf can be described as (Chen and Pawar, 2019; Schölkopf and Smola, 2002):

$\left(x_{i}, x_{j}\right)=\exp \left(-\gamma\left\|x_{i}-x_{j}\right\|_{2}^{2}\right), \gamma>0$.

By adapting the Lagrange multipliers, $\alpha_{\mathrm{i}}$ and $\alpha_{\mathrm{i}}{ }^{*}$, are determined, the predictive model can be describe as below (Chen and Pawar, 2019):

$g(\boldsymbol{x})=\sum_{i=1}^{N_{s}}\left(-\alpha_{i}+\alpha_{i}^{*}\right) K\left(x_{i}, \mathrm{x}\right)+b$.

The vector for the non-zero component of $\left(-\alpha_{\mathrm{i}}+\alpha_{\mathrm{i}}^{*}\right), i=1,2, \ldots, N_{\mathrm{s}}$, is called the support vectors. Given an input $x$, the SVR model can output all the support vectors. In this research, $C, \gamma$, and $\varepsilon$ are three tuning parameters for developing machine learning model. 


\subsubsection{Random Forest (RF)}

190 The Random Forest (RF) is adapted the capacity of decision tree and ensemble techniques to

191 generate reliable regression models. These models deliver intensive understanding into the data

192 tree by controlling the level of nonlinearity in the training databank (Breiman, 2001). The RF is

193 an extensive bagging and a solid opposer for boosting (Breiman, 2001). Also, the advantage of the

194 RF model enables each regression tree to include different combinations of the predictor variables

195 and prevents overfitting to the training dataset. This task is accomplished by switching Out-of-Bag

196 (OOB) samples from a specific predictor to evaluate the increase in estimation error while the 197 remaining factors are kept the same (Breiman, 2001). The mean square error $\left(\mathrm{MSE}_{\mathrm{OOB}}\right)$ is defined 198 as follows (Breiman, 2001; Chen and Pawar, 2019)

$$
\mathrm{MSE}_{\mathrm{OOB}}=\frac{1}{N_{T}} \sum_{i=1}^{N_{D T}}\left(y_{i}-\hat{y}_{i}\right)^{2}
$$

200 where, $N_{D T}$ presents for the number of OOB samples, and $\hat{y}_{i}$ knows as the OOB prediction for 201 training samples. In RF regression modelling, the following tuning parameters need to be specified 202 [33]: (i) the number of decision trees to grow in the random forest (N_estimators), (ii) the number 203 of randomly defined predictor variables at each node when searching for the best split 204 (Max_features), and (iii) the minimum number of observations is used for splitting an internal 205 node (min_samples_split). In this study, python's Scikit-Learn package, namely 206 "sklearn.ensemble.RandomForestRegressor" was used to develop RF predictive model 207 (Pedregosa et al., 2011). 


\subsubsection{Extreme Gradient Boosting (XGboost)}

210 XGBoost is an ensemble of classification and regression trees (CARTs) method developed by

211 (Chen and Guestrin, 2016). XGBoost-based regression is adapted a decision tree (DT) based on

212 the previous tree, adjusting DT proportion for creating step by step functionality (Gholami et al.,

213 2020; Shin et al., n.d.; Zhang et al., 2018). Also, out of 29 winning prizes in the machine learning

214 contest Kaggle in 2015, XGBoost was the most popular technique that 17 awards applied XGBoost

215 (Zhang et al., 2018). The higher-ranking performance of XGBoost in supervised machine learning

216 is the main reason it is selected to build the prediction model for $\mathrm{CO}_{2}$ trapping performance in this

217 study. The illustration of extreme gradient boosting depicts in Figure 3.

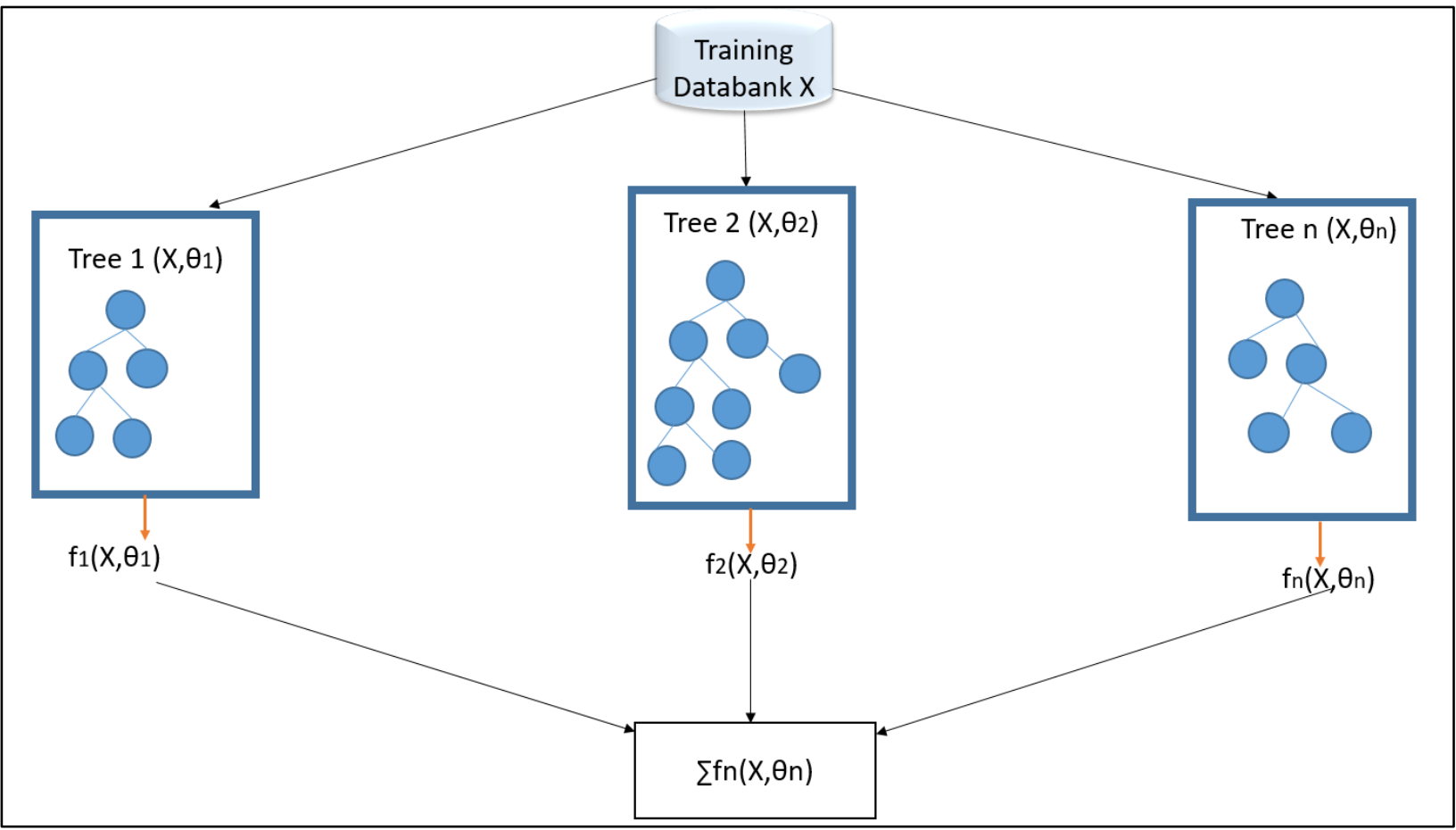

Figure 3. The illustration of XGboost technique

220 Firstly, the Xgboost has generated the difference between the prediction and data measurements to calculate the residual and misclassification. Then, the multiple regression tree models can 
222 appropriately evaluate the misclassification achieved in the first phase. Finally, the residuals after

223 the first two phases are adjusted to the other trees in the third phase, and this process is repeated

224 many times (Sutton, 2005). This process leads to the final goal of XGboost that is simplified for 225 optimization of the training loss $(\mathrm{m})$ and regulations $(\beta)$. The $\mathrm{f}_{\mathrm{p}}$ stands for the function of the $\mathrm{P}-$

226 tree. The objective function $(K)$ in round $g$ is given by the following formula [62-64]:

$227 \quad K^{(g)}=\sum_{i=0}^{n} m\left(y_{i}+\breve{y}_{l}\right)+\sum_{n=1}^{P} \beta\left(f_{p}\right)$

228 In this work, $y_{i}$ represents for the simulation $\mathrm{CO}_{2}$ trapping efficiency from databank, and $\breve{y}_{l}$ stands

229 for the prediction values from XGboost model. The XGBregressor library of Scikit-learn's python

230 package is adapted for training ML model. The tunning hyperparameter was used for XGboost,

231 including number of a tree (N_estimator), minimum loss reduction for doing a split (gamma),

232 maximum depth of a tree (max_depth), step of each weight (learning_rate), L1 regularization of

233 leaf weight (reg_lambda), and L2 regularization of leaf weight (reg_alpha) (Pedregosa et al., 2011).

\section{$234 \quad$ 2.3. Workflow of developing machine learning models}

235 The framework of the machine learning (ML) model for predicting $\mathrm{CO}_{2}$ trapping performance in 236 deep saline aquifers consists of several steps, as depicted in Figure 4. 


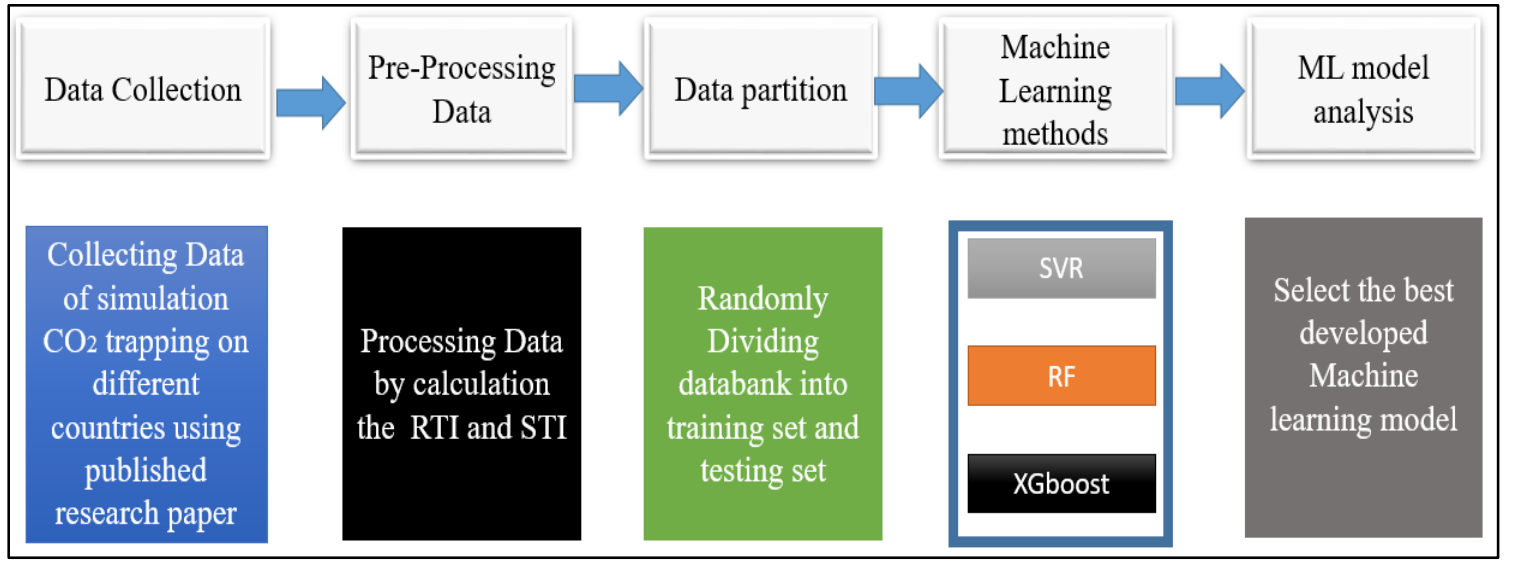

Figure 4. The schematic of machine learning modelling process

243 The procedure of developing ML models starts with data collection and then pre-processing 244 input/output data. The next phase starts with a data portion that randomly divided the whole 245 databank into two sets (training and testing). The following process is the employment of proposed 246 ML techniques for target data. Then, the performances of each developed model are analyzed to 247 define the best model from three ML algorithms for deployment in predicting $\mathrm{CO}_{2}$ trapping 248 efficiency in saline formations. In the developing ML model, the data partition is the necessary 249 process. This step has separated the database into two groups, including train and test groups. The 250 training group is a subset to develop the training model, while the testing group utilizes for 251 evaluating the performance of predictive models. Unfortunately, there is no specific principle for 252 dividing the ratio of partitioning data into training and testing. The previous work has found that 253 the percentage of training data influences the accuracy of ML model (Ali, 2021). To improve the 254 accuracy of the outputs for ML model, several options of data proportions need to consider for the 255 training model. To address this issue, the entire databank is divided into four partitions as follows: $60 \%-40 \%, 70 \%-30 \%, 80 \%-20 \%, 90 \%-10 \%$, while the first partition is the training group and the 
257 second part stands for the test group. However, the critical issue is how we can select the best ML 258 model among the three techniques. To solve this problem, two popular statistical indicators are 259 chosen; namely, coefficient of determination (R-square) and root mean squared error (RMSE). 260 These indicators determined using the following formula:

$$
R-\text { squared }=1-\frac{\sum_{i=1}^{n}\left(T_{i, \text { sim }}-T_{i, \text { pred }}\right)^{2}}{\sum_{i=1}^{n}\left(T_{i, \text { sim }}-\bar{T}_{i, \text { sim }}\right)^{2}}
$$

$$
R M S E=\sqrt{\frac{1}{n} \sum_{i=1}^{n}\left(T_{i, s i m}-T_{i, p r e d}\right)^{2}}
$$

263 T denotes the residual and solubility trapping efficiency in saline aquifers; subscripts sim and

264 pred represent the simulation and predicted results, respectively; $\bar{Y}$ stands for average residual

265 and solubility trapping, and $\mathrm{n}$ is the number of the training data point.

\section{3. Result and Discussion}

267 Before analyzing the prediction performance for developing ML models in this study, a brief 268 description of the tuning hyperparameters applied in each method is presented first.

\section{3.1. Hyperparameter tuning ML models}

270 In addition, the ML methods need a lot of number hyperparameters for training models. However,

271 there are only several essential parameters to be used for achieving the best model performance.

272 The grid search technique adapts for selecting the best tuning hyperparameter for each ML method

273 in this work. Table 2 highlights the information of tuning parameters applied for developing the 
274 three predictive machine learning models. All of the training and testing scenarios were conducted 275 using open-source Scikit-learn's python package.

276 Table 2. The parameter for tuning ML models in this study

\begin{tabular}{llll}
\hline Model & Parameter & $\begin{array}{l}\text { Specific search } \\
\text { range }\end{array}$ & Optimal values \\
\hline SVR & $\gamma$ & $10-200$ & 100 \\
XGboost & $C$ & $5-1000$ & 100 \\
& N_estimator & $100-10000$ & 9000 \\
& Reg_lamda & $0.01-100$ & 4 \\
& Max_depth & $10-1000$ & 600 \\
& Learning_rate & $0.001-1$ & 0.01 \\
RF & Reg_alpha & $0.001-1$ & 0.01 \\
& N_estimator & $100-6000$ & 6000 \\
& Min_sample split & $10-100$ & 40 \\
& Min_sample leaf & $0.5-1.0$ & 0.95 \\
\hline
\end{tabular}

3.2. Performance of each ML model

The four scenarios of databank portions were considered to determine the best ML method. The

279 prediction results of three ML models are highlighted in Table X. As can be observed from this

280 table, the developed ML models in this work can obtain an accuracy of $90 \%$ for training and testing

281 phases on all scenarios of data proportions. These results indicated that the three ML models had

282 predicted well in $\mathrm{CO}_{2}$ trapping efficiency in saline aquifers using 1509 data samples.

By observation overall ML models performance on each data division, it can be found that the

284 XGboost method has the highest prediction accuracy over XGboost and SVR. The excellent 285 performance of XGboost could observe in Table 3. This table is considered as for proven the best 286 data bank proportions. The XGboost model attains the stable prediction results of training and 287 testing for all data portions. Among four data portions, the XGBoost model achieved the highest 288 prediction accuracy on data portions, 80\%-20\%. 
Table 3. The performance of three ML models for prediction trapping index in saline aquifers.

\begin{tabular}{|c|c|c|c|c|c|c|c|c|c|}
\hline \multirow{3}{*}{$\begin{array}{c}\text { Databank } \\
\text { portions }\end{array}$} & \multirow{3}{*}{ Model } & \multicolumn{4}{|c|}{ RTI } & \multicolumn{4}{|c|}{ STI } \\
\hline & & \multicolumn{2}{|c|}{ Training } & \multicolumn{2}{|c|}{ Test } & \multicolumn{2}{|c|}{ Training } & \multicolumn{2}{|c|}{ Test } \\
\hline & & $\mathrm{R}^{2}$ & RMSE & $\mathrm{R}^{2}$ & RMSE & $\mathrm{R}^{2}$ & RMSE & $\mathrm{R}^{2}$ & RMSE \\
\hline \multirow[b]{3}{*}{$60 \%-40 \%$} & SVR & 0.9412 & 0.0713 & 0.9230 & 0.0767 & 0.9049 & 0.0146 & 0.9004 & 0.0316 \\
\hline & $\mathrm{RF}$ & 0.9971 & 0.0126 & 0.9801 & 0.0322 & 0.9980 & 0.0074 & 0.9908 & 0.0164 \\
\hline & XGBoost & 0.9996 & 0.0046 & 0.9913 & 0.0226 & 0.9997 & 0.0028 & 0.9668 & 0.0311 \\
\hline \multirow[b]{3}{*}{$70 \%-30 \%$} & SVR & 0.9421 & 0.0707 & 0.9181 & 0.0769 & 0.9049 & 0.2871 & 0.9139 & 0.2756 \\
\hline & $\mathrm{RF}$ & 0.9977 & 0.0113 & 0.9753 & 0.0354 & 0.9984 & 0.0065 & 0.9914 & 0.016 \\
\hline & XGBoost & 0.9996 & 0.0043 & 0.9946 & 0.0181 & 0.9997 & 0.0027 & 0.9974 & 0.0088 \\
\hline \multirow[b]{3}{*}{$80 \%-20 \%$} & SVR & 0.9403 & 0.0707 & 0.9254 & 0.0759 & 0.9062 & 0.2843 & 0.9191 & 0.2847 \\
\hline & $\mathrm{RF}$ & 0.9984 & 0.0095 & 0.9686 & 0.0410 & 0.9990 & 0.0051 & 0.9868 & 0.0208 \\
\hline & XGBoost & 0.9997 & 0.0041 & 0.9941 & 0.0191 & 0.9998 & 0.0026 & 0.9985 & 0.0065 \\
\hline \multirow[b]{3}{*}{$90 \%-10 \%$} & SVR & 0.9403 & 0.0707 & 0.9133 & 0.0792 & 0.9094 & 0.2901 & 0.9107 & 0.2837 \\
\hline & $\mathrm{RF}$ & 0.9986 & 0.0086 & 0.9451 & 0.0544 & 0.9991 & 0.0049 & 0.9780 & 0.02869 \\
\hline & XGBoost & 0.9997 & 0.0076 & 0.9916 & 0.0241 & 0.9998 & 0.0024 & 0.9979 & 0.0080 \\
\hline
\end{tabular}

291

292 On the other hand, SVR model has the least accuracy for prediction results on four data divisions.

293 Therefore, the overall performance ranking in terms of statistical indicators is XGboost, RF, and

294 SVR. Also, the data division of $80 \%-20 \%$ is used for further evaluation in this study. This data

295 division achieves excellent testing performance over three remaining data divisions.For better

296 visualization, the cross plot of testing performance using data-division $80 \%-20 \%$ by three ML

297 models for prediction RTI and STI is illustrated in Figure 5. These plots strongly demonstrate that

298 the XGboost is superior to RF and SVR. As shown in Figure 5, the testing points of XGboost

299 distribution nearby the perfect fitting line indicate the excellent agreement between model

300 prediction and simulation data. From the view of R-squared, the Xgboost model achives the

301 better testing effect, and its $\mathrm{R}^{2}$ value of RTI and STI equal to 0.9941 and 0.9985 ,

302 respectively. The testing effect of SVR model is the worse, and its R-squared value of 
RTI and STI is 0.9254 and 0.9191, respectively. The R-square values of the three ML models are typically above 0.92 , which indicates that the ML proposed in this study 305 have achieved the good agreement between reservoir simulation data and predictive 306 results.

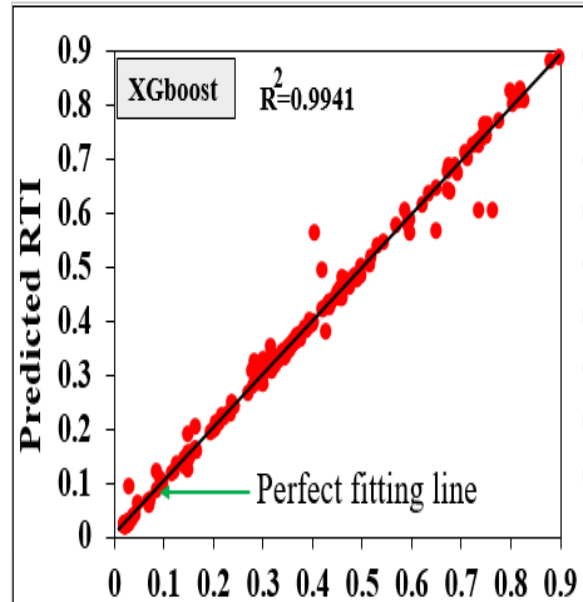

a.

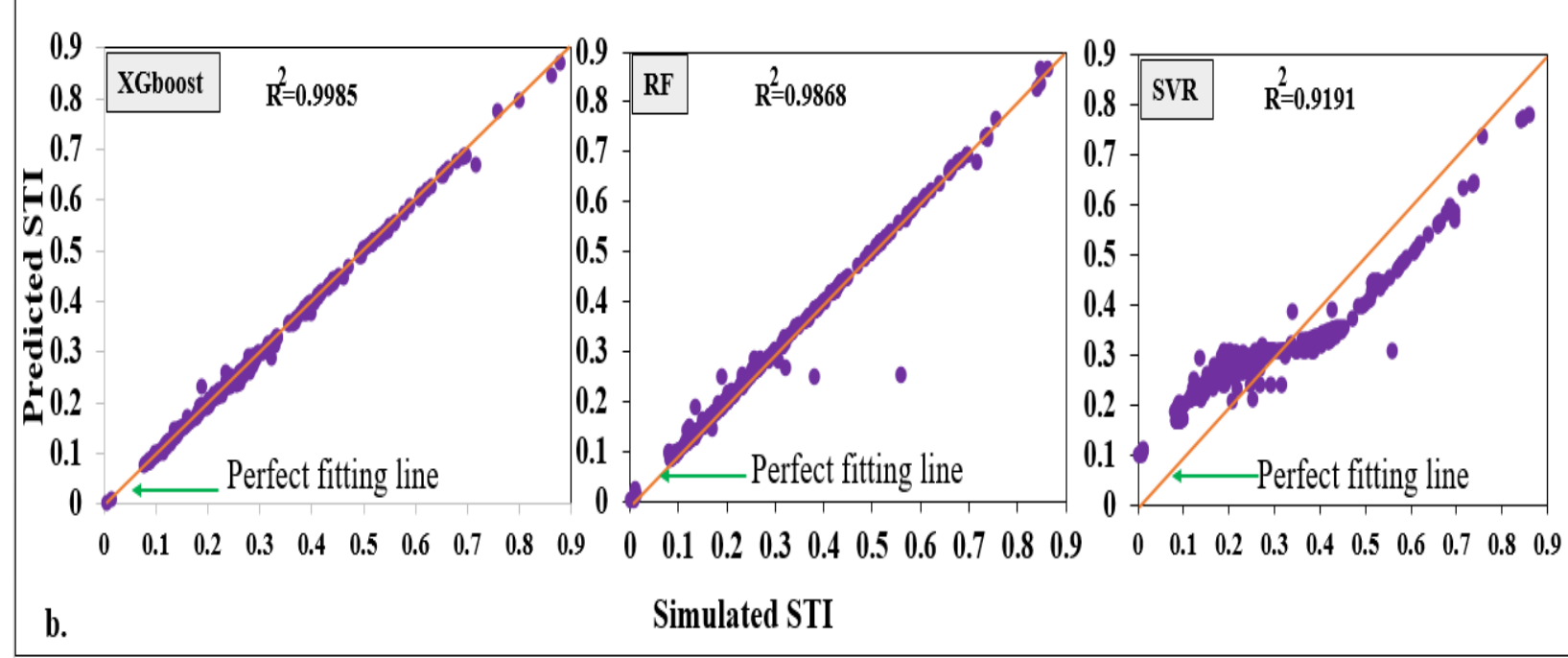

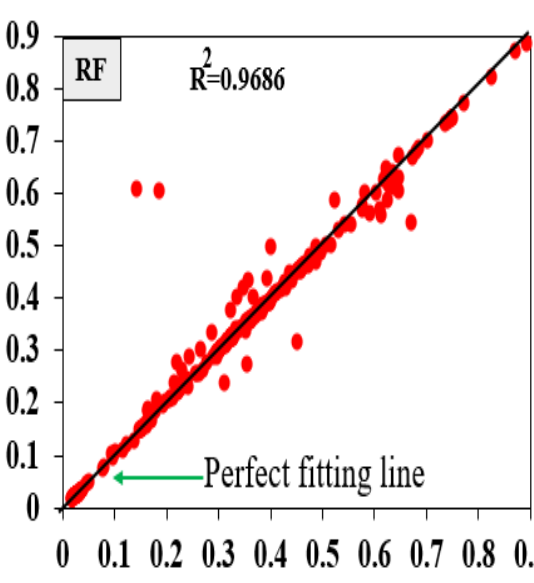

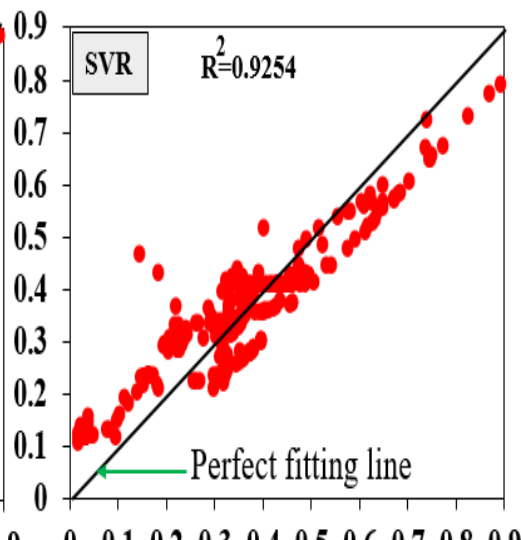

Simulated RTI

Figure 5. The fitting plots between simulated and predicted trapping efficiency for three ML models in testing phase 
Moreover, for a better evaluate the performance of testing RTI and STI, bar charts of RMSE and $\mathrm{R}^{2}$ are presented in Figure 6. Overall, Xgboost shows a better performance than RF and SVR in prediction $\mathrm{CO}_{2}$ trapping efficiency. Thus, Xgboost is the most predictable ML model thanks to its highest testing $\mathrm{R}^{2}$ and lowest RMSE. It can be remarked from Table 3 and Figure $\mathbf{6}$ that our nominated ML models to predict RTI and STI in saline aquifers follow the reliable ranking highlight below: Xgboost > RF > SVR
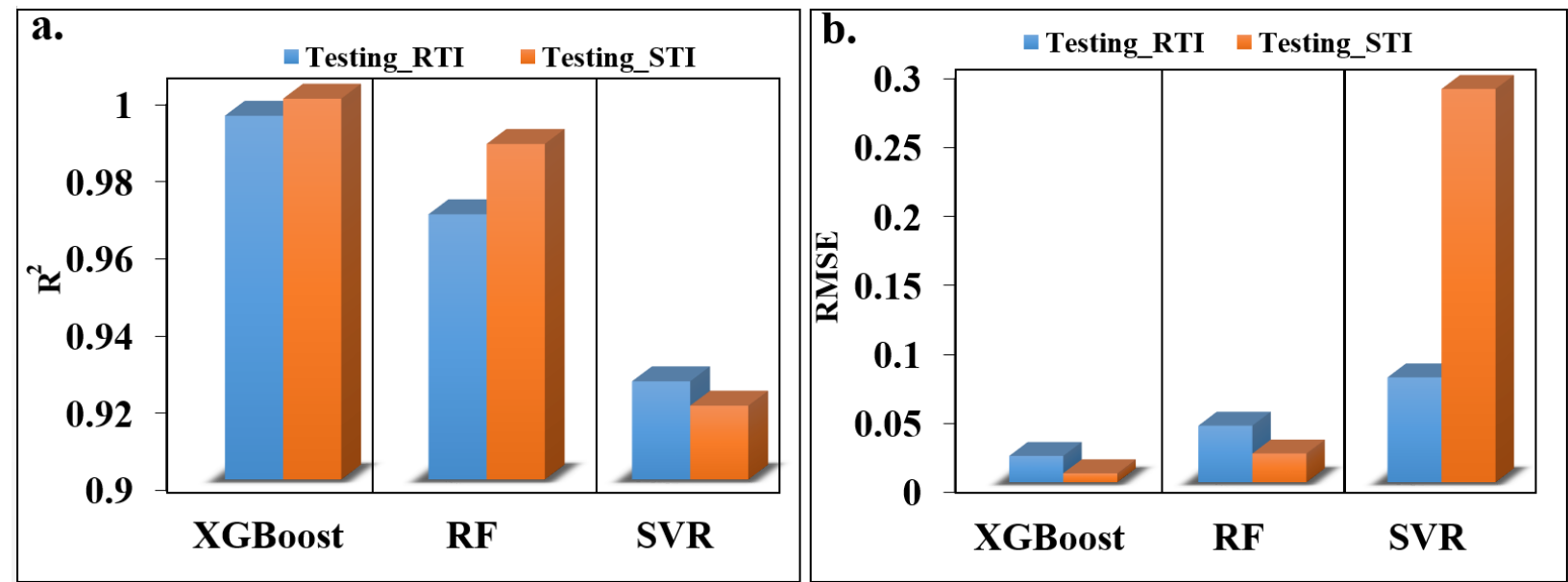

Figure 6. The comparison status of RMSE and $\mathrm{R}^{2}$ of nominated ML models for estimation $\mathrm{CO}_{2}$ trapping efficiency.

314 The better performance of XGboost in both $\mathrm{R}^{2}$ and RMSE is demonstrated the robustness of this model for prediction $\mathrm{CO} 2$ trapping efficiency. This evidence is the clear manner for demonstration the superior of XGBoost over RF and SVR. In addition, the quality of Xgboost model could be observed to deep insight by comparing the estimated $\mathrm{CO}_{2}$ efficiency in brine formations using XGboost and the simulated testing dataset for RTI (Figure 7a) and STI (Figure 7b). The excellent fitting between simulated trapping efficiency and XGboost prediction results in the testing stage can be seen in these subfigures. Thus, all graphical analyses figure out that the XGboost is the best method in this study. Therefore, XGboost model is selected for further investigation before employing it in the actual application. 


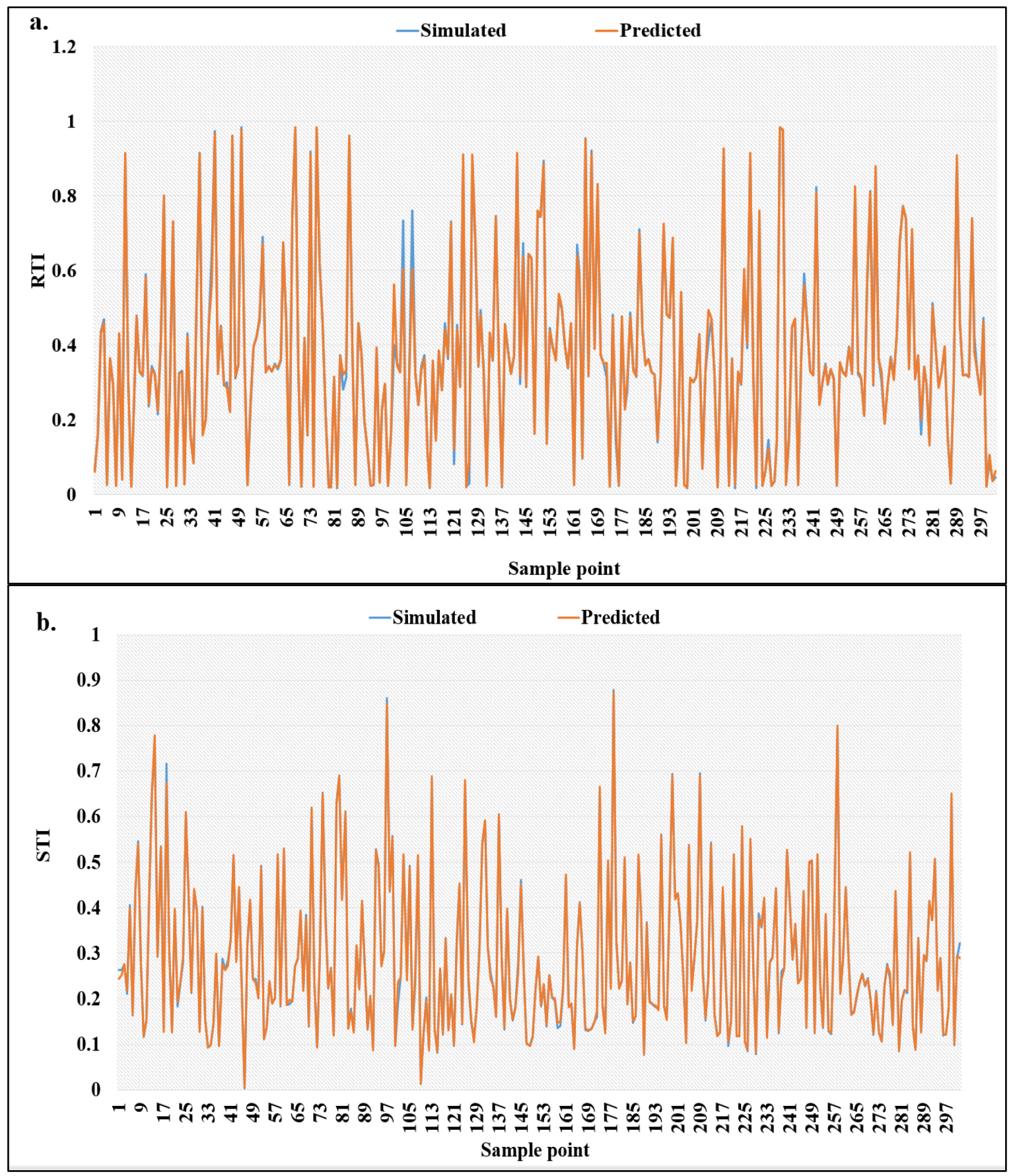

Figure 7. The relationship of simulated and predicted trapping efficiency by considering each sample testing data. (a) RTI and (b) STI 


\subsection{Relative important of influence predictors}

$326 \mathrm{CO}_{2}$ sequestration in saline aquifers has a lot of essential variables effect to trapping efficiency.

327 Thus, the crucial variables of XGboost model need to be evaluated to understand the significance

328 of each input feature on the $\mathrm{CO}_{2}$ trapping efficiency in saline reservoirs. This study adopts built in

329 function in scikit-learnin library for evalution each input variable. Figure 8 depicts the result of

330 ranking important features for residual trapping and solubility trapping in this study.

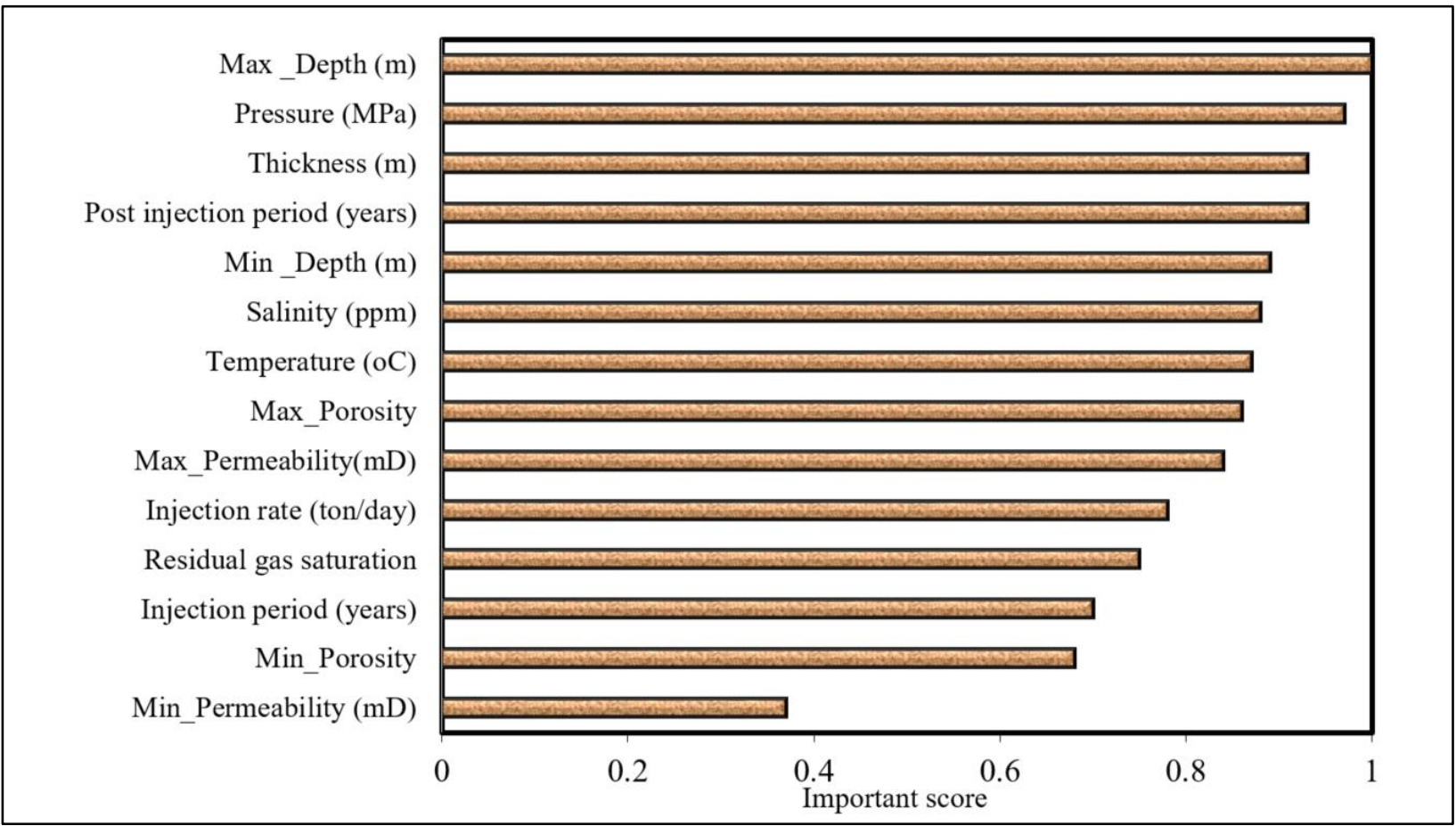

332 Figure 8. Essential features are ranking for ML models

333 By visualization of the bar chart, it can be found that the max_depth is an essential feature for both

334 RTI and STI in saline reservoirs. This finding is an important notice for trapping efficiency because

335 depth is also affected by structural trapping capacity in saline formation. In the most recent

336 research, Iglauer et al. (Iglauer, 2018) figured out an issue in achieving an optimum storage depth

337 where the maximum amount of $\mathrm{CO}_{2}$ structural trapping happens in a deep saline reservoir. 
338 Furthermore, $\mathrm{CO}_{2}$ solubility is a function of depth in the subsurface (Duan et al., 2006). In addition,

339 Kim et al. (Kim et al., 2017) also demonstrated that increasing depth leads to increased residual

340 and solubility trapping efficiency in deep saline formation. Therefore, there is an agreement

341 between the previous study and our work. In consequence, the max_depth is found as the highest-

342 ranking feature in XGboost model.

343 Besides, the crucial feature is listed out from ML model. The fewer effect features are also

344 remarked for our study. By considering the ranking charts in Figure 8, the minimum porosity,

345 minimum permeability can be removed from the developed ML model. Moreover, the collection

346 of data information with accuracy is complex in subsurface storage sites. Therefore, the developed

347 model with fewer input features could help us to verify and easily employ the developed ML

348 models in the actual application of the geo-sequestration project.

\subsection{Comparison of the best ML model with previous models}

350 Although the XGboost model is demonstrated as the highest accuracy over RF and SVR, it is 351 necessary to prove the robustness of our developed models with the previous study. Therefore, the 352 performance of XGboost is re-evaluated with previously developed ML models in the reliable 353 published paper. Table 4 highlights the statistical indicators for different ML methods. It is found 354 that the XGboost model is superior to the other ML models, as confirmed by the highest $\mathrm{R}^{2}$ and 355 lowest RMSE for both training and testing phases.

356 Table 4. The comparison analysis for demonstration the robust of nominated ML model

\begin{tabular}{|c|c|c|c|c|c|c|}
\hline \multicolumn{2}{|c|}{} & \multicolumn{2}{c|}{ Training } & \multicolumn{2}{c|}{ Testing } \\
\hline Methods & Library & Number of samples & RMSE & $\mathrm{R}^{2}$ & RMSE & $\mathrm{R}^{2}$ \\
\hline XGboost ( This study) & Scikit-learn & 1509 & 0.0041 & 0.9998 & 0.0065 & 0.9985 \\
\hline ANN (Song et al., 2020) & Tensorflow & 145500 & 0.0080 & 0.9842 & 0.0082 & 0.9847 \\
\hline
\end{tabular}


357 For the training phases, the RMSE and $\mathbf{R}^{2}$ from XGBoost evaluations are 0.0041 and 0.9998 , 358 respectively, whereas the RMSE and $\mathrm{R}^{2}$ of ANN models are 0.9842 , respectively.

359 Regarding the testing phase, the RMSE and $\mathrm{R}^{2}$ for XGBoost evaluations are 0.0065 and 0.9985 , 360 respectively, while the RMSE and $\mathrm{R}^{2}$ of the ANN model are 0.0082 and 0.9847 , respectively.

361 Moreover, for better visualization of our comparison, Figure 9 presents the bar plots of RMSE 362 and $\mathrm{R}^{2}$ for two ML models. The significant difference of statistical indicators in our study and 363 previous work demonstrated that the XGboost model has better accuracy than other models by 364 observing the bar plots.

365 To verify the predictability of XGboost in prediction RTI and STI in saline aquifers compared to 366 the ANN model of Song et al. by using the same range of input features. Also, Song et al. [10] 367 were used CMG-GEM simulation to conduct the reservoir simulation results for 300 years, 368 including 10 years injection and 290 years post-injection, then compare the simulated results and 369 ANN prediction. Our study updated the field simulation data from Song et al. [10] for predictive 370 purposes to capture their idea. For better observation, the prediction results of two ML models and 371 simulation results exhibit in Figure 10. As can be observed in this figure, the $\mathrm{CO}_{2}$ trapping 372 efficiency of XGboost achieves higher accuracy than the outputs from the multilayer ANN model. 373 Furthermore, the advantage of our developed model utilizes less sample training data than the 374 previous study. In this work, Xgboost has used 1509 samples while the existing research used 375145500 data samples. The ML mechanism plays an essential role in determining the suitable 376 number of training samples. Thus, the predictive-based ML should consider different methods in 377 the same training databank to select the suitable one for a specific study. 

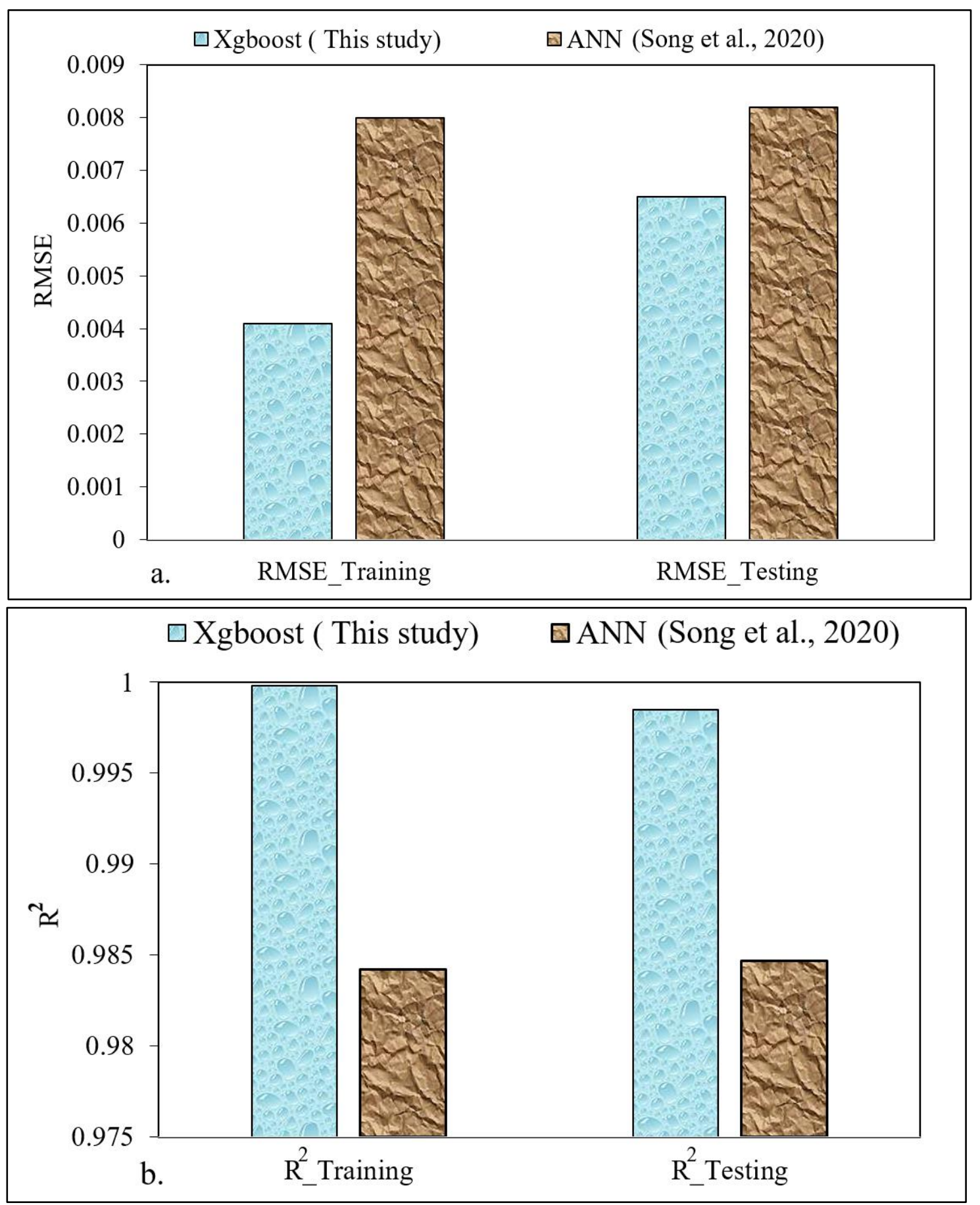

Figure 9. Comparison study of our model and existing study for predicting $\mathrm{CO}_{2}$ trapping 

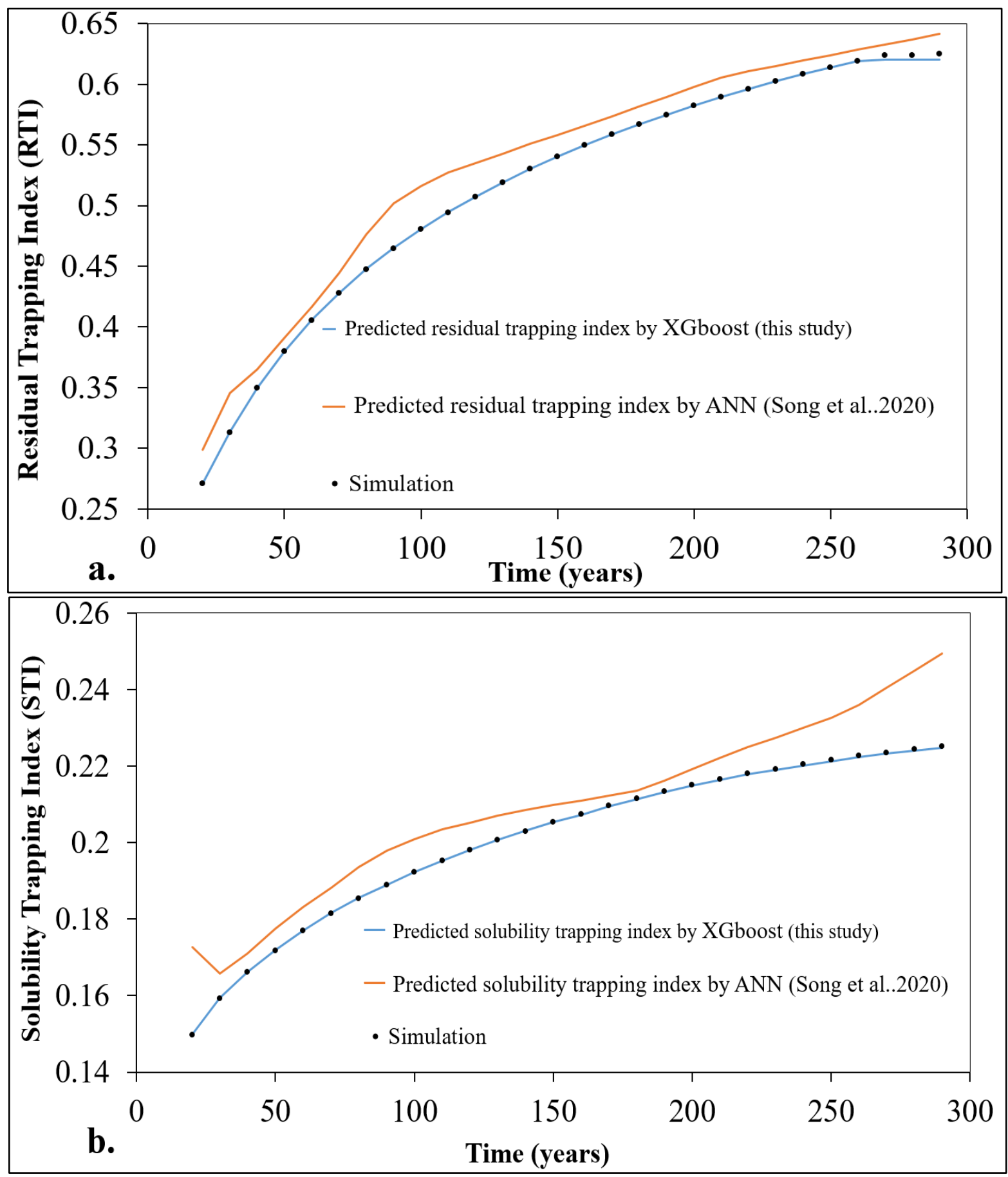

Figure 10. The comparison performance of XGboost and previous model with simulation. The XGboost exhibist the excellent fitting with simulation data by visualization the time series of RTI (a) and STI (b) 


\subsection{Xgboost model application perspective}

380 The XGboost model of this study employed the supervised ML technique for predicting the $\mathrm{CO}_{2}$ 381 trapping efficiency in saline aquifers considering geological and operation factors available from

382 the published paper. Specified a marked set of input-output pairs XGboost $=\left\{\left(p_{i}, t_{i}\right)\right\}_{i=1}^{n}$, the initial 383 objective of each ML model is to create a map for the predictor $p$ and the targets $t$ (Ali, 2021) . 384 This data part is defined as the training set. The ultimate objective of ML models build a sketch 385 that will derive well in a database that the ML models have never learned. The blind data is adapted 386 for estimating how well the ML models derive for specific studies. Also, these bling testing data 387 are considered for uncertainty analysis in the prediction ML model. For instance, to employ the 388 XGboost method as the best predictive method predicted the residual and solubility trapping in an 389 interest saline formation. The predictors of this saline formation that are not included in the training 390 set are collected first and processed in an excel format or text file. Then, the trained XGboost 391 model is loaded by joblib function in Scikit-learn python toolkit. Finally, they load the input 392 predictors to predict $\mathrm{CO}_{2}$ trapping efficiency for interest saline formation whose features are stored 393 in the input excel file.

394 The predictive results of ML models would help reservoir engineers deeply understand the $\mathrm{CO}_{2}$ 395 trapping efficiency that is useful for short-term and long-term monitoring $\mathrm{CO}_{2}$ storage projects.

396 In addition, the ML help to know the impact of each predictor/feature on the $\mathrm{CO}_{2}$ trapping 397 efficiency in saline aquifers that will provide a valuable tool for searching the suitable values of 398 input variables for reducing the uncertainty in the $\mathrm{CO}_{2}$ storage project. 


\subsection{Applicability domain of the XGboost model}

402 The simulation results collected in the published papers related to several uncertainty factors.

403 Therefore, determining the legality of these data and analyzing the Xgboost of the application 404 domain is necessary. To address this issue, the Willams plot was considered for our study. The

405 Williams plot highlights the applicability domain of the ML model. This plot is drawn by 406 considering the standardized residual (SR) and leverage values (Godall et al., 1993). The statistical 407 step for the Leverage parameter can be found in (Sarapardeh et al., 2016). Figure 11 shows the 408 Williams plot for the XGBoost model.

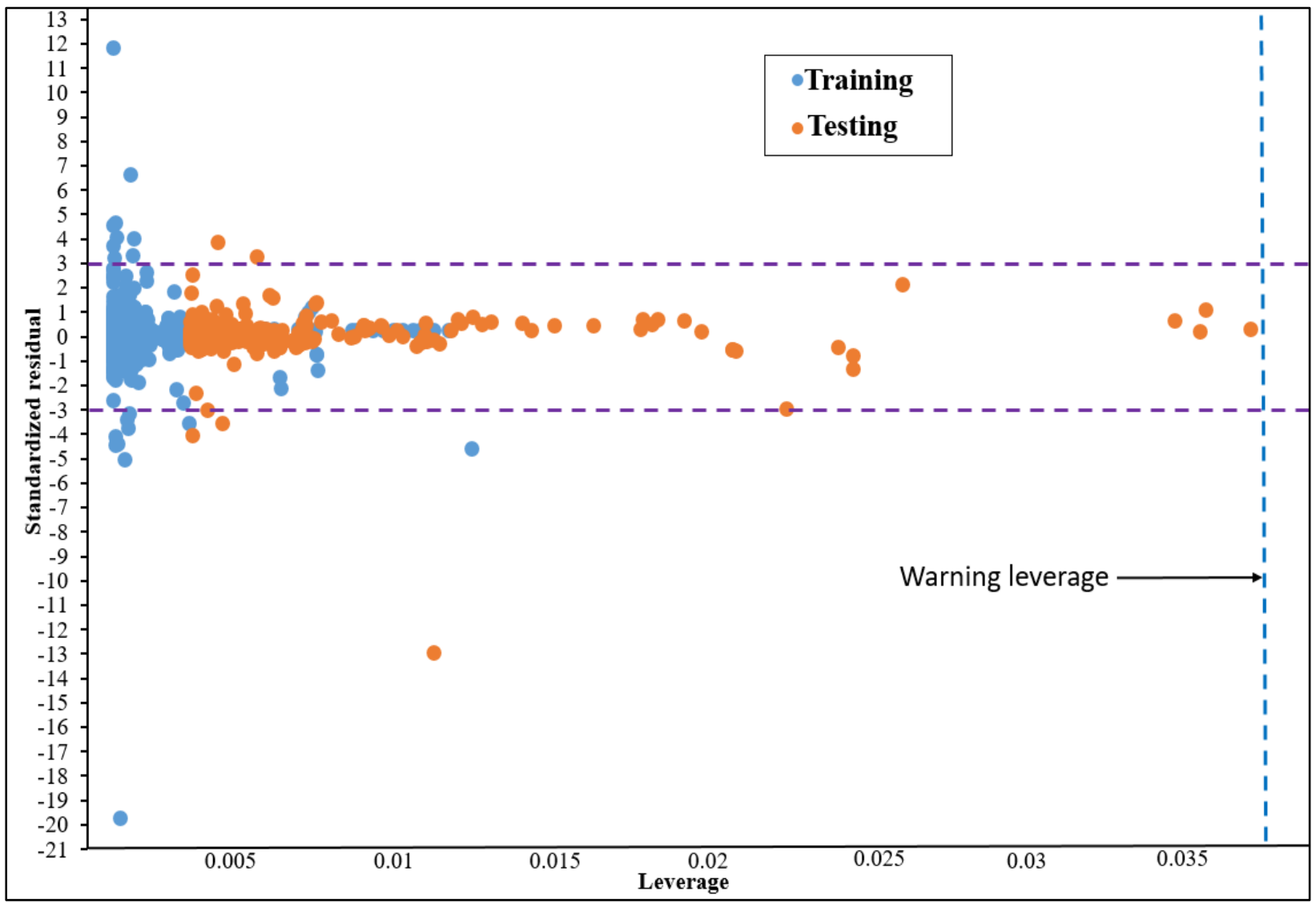

Figure 11. The Williams plot demonstrates the applicaton domain of XGboost models 
411 It can be analyzed from this plot, a massive part of the training and testing results are in the range

412 of $-3 \leq \mathrm{SR} \leq 3$. So, in a nutshell, the Xgboost model has a high level of reliability and statistics

413 trueness.

414 Moreover, it is underlined that just 24 points from the XGboost model's feasibility realm were

415 identified as outliers. It's worth noting that this number of suspicious data points only accounts for

$416 \quad 1.59 \%$ of entire datasets.

417 Ultimately, it is necessary to point out that the constructed Xgboost model should be employed to 418 predict the residual and solubility $\mathrm{CO}_{2}$ trapping in saline aquifers when input features inside the 419 proposed applicable ranges. Nevertheless, the developed ML model can be adapted for scenarios 420 outside the offered study range with caution because the accuracy model is not guaranteed. It can 421 produce accurate forecasts for some values of the parameters used but erroneous predictions for 422 others. Indeed, because the Xgboost model was built with general predictors characteristics, it may 423 be used for a wide variety of instances with features that fall in the range of the abovementioned 424 inputs.

425

426

427

428

429

430

431

432

433 


\section{Conclusions}

In this study, three machine learning techniques, namely XGboost, RF, and SVR, were developed reliable ML models to estimate the solubility trapping index and residual trapping index for deep saline reservoirs. Based on the results, the following vital conclusions could be underlined:

- The employment ML models obtained excellent performance in predicting $\mathrm{CO}_{2}$ trapping index in deep saline reservoirs.

- XGboost model is found as the most predictable model in prediction $\mathrm{CO}_{2}$ trapping index in saline aquifers. Furthermore, the Xgboost outperforms RF and SVR.

- XGboost reveals the highest $\mathrm{R}^{2}$ and lowest RMSE for both training and testing phases in this work.

- The Xgboost is superior to other ML models in the published literature that demonstrated the robustness of developed models.

- The maximum depth is an essential feature for residual and solubility trapping to find out from this work.

- The minimum porosity and permeability have the most negligible impact on to Xgboost model for predicting trapping index in this work.

- The highlight of this work is used fewer training data samples than previous. It is the advantage of this work to develop reliable $\mathrm{ML}$ models for predicting $\mathrm{CO}_{2}$ trapping performance. Our developed models help predict the feasibility of the $\mathrm{CO}_{2}$ storage project in the early phase.

- Also, this research was paid attention to the diversity of reservoir characteristic saline formation, whereas previous work used a homogenous reservoir model for generating data 
465 for financial support.

466 
480

481

482

483

484

485

486

487

488

489

490

491

492

493

494

495

496

497

498

499

500

501

Abas, N., Khan, N., 2014. Carbon conundrum , climate change , CO 2 capture and consumptions. Biochem. Pharmacol. 8, 39-48. https://doi.org/10.1016/j.jcou.2014.06.005

Ahmadi, M.A., Kashiwao, T., Rozyn, J., Bahadori, A., 2016. Accurate prediction of properties of carbon dioxide for carbon capture and sequestration operations. Pet. Sci. Technol. 34, 97103. https://doi.org/10.1080/10916466.2015.1107847

Ahmadi, M.A., Soleimani, R., Lee, M., Kashiwao, T., Bahadori, A., 2015. Determination of oil well production performance using artificial neural network (ANN) linked to the particle swarm optimization (PSO) tool. Petroleum 1, 118-132.

https://doi.org/10.1016/j.petlm.2015.06.004

Ajayi, T., Awolayo, A., Gomes, J.S., Parra, H., Hu, J., 2019. Large scale modeling and assessment of the feasibility of CO2 storage onshore Abu Dhabi. Energy 185, 653-670. https://doi.org/10.1016/j.energy.2019.07.052

Al-khdheeawi, E.A., Vialle, S., Barifcani, A., Sarmadivaleh, M., Iglauer, S., 2018. Impact of Injection Scenario on CO2 Leakage and CO2 Trapping Capacity in Homogeneous Reservoirs Model description and initialization, in: Offshore Technology Conference Asia. Kuala Lumpur, Malaysia.

Al-Khdheeawi, E.A., Vialle, S., Barifcani, A., Sarmadivaleh, M., Iglauer, S., 2018a. Effect of wettability heterogeneity and reservoir temperature on $\mathrm{CO} 2$ storage efficiency in deep saline aquifers. Int. J. Greenh. Gas Control 68, 216-229. https://doi.org/10.1016/j.ijggc.2017.11.016

Al-Khdheeawi, E.A., Vialle, S., Barifcani, A., Sarmadivaleh, M., Iglauer, S., 2018b. Enhancement of $\mathrm{CO} 2$ trapping efficiency in heterogeneous reservoirs by water-alternating 
gas injection. Greenh. Gases Sci. Technol. 12, 1-12. https://doi.org/10.1002/ghg.1805

503

504

505

506

507

508

509

510

Al-Khdheeawi, E.A., Vialle, S., Barifcani, A., Sarmadivaleh, M., Zhang, Y., Iglauer, S., 2018c. Impact of salinity on $\mathrm{CO} 2$ containment security in highly heterogeneous reservoirs. Greenh. Gases Sci. Technol. 8, 93-105. https://doi.org/10.1002/ghg.1723

Ali, A., 2021. Data-driven based machine learning models for predicting the deliverability of underground natural gas storage in salt caverns. Energy 229, 120648. https://doi.org/10.1016/j.energy.2021.120648

Amar, N., Hemmati-sarapardeh, A., Varamesh, A., 2019. Predicting solubility of CO2 in brine by advanced machine learning systems : Application to carbon capture and sequestration. J. CO2 Util. 33, 83-95. https://doi.org/10.1016/j.jcou.2019.05.009

Aminu, M.D., Nabavi, S.A., Rochelle, C.A., Manovic, V., 2017. A review of developments in carbon dioxide storage. Appl. Energy 208, 1389-1419. https://doi.org/10.1016/j.apenergy.2017.09.015

Anchliya, A., Ehlig-Economides, C.A., Jafarpour, B., 2012. Aquifer Management To Accelerate CO2 Dissolution and Trapping. SPE J. 17, 805-816. https://doi.org/10.2118/126688-PA

Bachu, S., 2008. CO2storage in geological media: Role, means, status and barriers to deployment. Prog. Energy Combust. Sci. 34, 254-273. https://doi.org/10.1016/j.pecs.2007.10.001

Baz, H., Noureldin, M., Allinson, W.G., Cinar, Y., 2016. A field-scale investigation of residual and dissolution trapping of $\mathrm{CO} 2$ in a saline formation in Western Australia. Int. J. Greenh. Gas Control 46, 86-99. https://doi.org/10.1016/j.ijggc.2015.12.032

Boot-Handford, M.E., Abanades, J.C., Anthony, E.J., Blunt, M.J., Brandani, S., Dowell, N. Mac, 2014. Carbon capture and storage update. Energy Environ. Sci. 7, 130-189. 
https://doi.org/10.1039/c3ee42350f

526

527

528

529

530

531

532

533

534

535

536

537

538

539

540

541

542

543

544

545

546

547

Breiman, L.E.O., 2001. Random Forests. Mach. Learn. 45, 5-32.

Chen, B., Pawar, R.J., 2019. Characterization of CO2 storage and enhanced oil recovery in residual oil zones. Energy 183, 291-304. https://doi.org/10.1016/j.energy.2019.06.142

Chen, T., Guestrin, C., 2016. XGBoost : A Scalable Tree Boosting System, in: ACM SIGKDD International Conference on Knowledge Discovery and Data Mining. San Francisco, CA, USA, pp. 785-794.

Dai, Z., Stauffer, P.H., Carey, J.W., Middleton, R.S., Lu, Z., Jacobs, J.F., Hnottavange-Telleen, K., Spangler, L.H., 2014. Pre-site characterization risk analysis for commercial-scale carbon sequestration. Environ. Sci. Technol. 48, 3908-3915. https://doi.org/10.1021/es405468p

Dai, Z., Viswanathan, H., Middleton, R., Pan, F., Ampomah, W., Yang, C., Jia, W., Xiao, T., Lee, S., Mcpherson, B., Balch, R., Grigg, R., White, M., 2016. CO 2 Accounting and Risk Analysis for CO 2 Sequestration at Enhanced Oil Recovery Sites. https://doi.org/10.1021/acs.est.6b01744

Dai, Z., Zhang, Y., Stauffer, P., Xiao, T., Zhang, M., Ampomah, W., Yang, C., Zhou, Y., Ding, M., Middleton, R., Soltanian, M.R., Bielicki, J.M., 2017. Injectivity Evaluation for Offshore CO 2 Sequestration in Marine Sediments. Energy Procedia 114, 2921-2932. https://doi.org/10.1016/j.egypro.2017.03.1420

Date, N.E., 2014. Ye Zhang 1; Guang Yang 2; and Shuiquan Li 323 1-14. https://doi.org/10.1061/(ASCE)HZ.2153-5515.0000246.

Dejam, M., Hassanzadeh, H., 2018. Diffusive leakage of brine from aquifers during CO 2 geological storage. Adv. Water Resour. 111, 36-57. https://doi.org/10.1016/j.advwatres.2017.10.029 
Duan, Z., Sun, R., Zhu, C., Chou, I., 2006. An improved model for the calculation of CO2 solubility in aqueous solutions containing $\mathrm{Na}+, \mathrm{K}+, \mathrm{Ca} 2+, \mathrm{Mg} 2+, \mathrm{Cl}$, and $\mathrm{SO} 4$. Mar. Chem. 98, 131-139. https://doi.org/10.1016/j.marchem.2005.09.001

Foroozesh, J., Dier, M.A., Rezk, M.G., 2018. A simulation study on CO 2 sequestration in saline aquifers : Trapping mechanisms and risk of CO 2 leakage, in: MATEC Web of Conferences. p. 5.

Gholami, H., Mohamadifar, A., Collins, A.L., 2020. Spatial mapping of the provenance of storm dust: Application of data mining and ensemble modelling. Atmos. Res. 233, 104716. https://doi.org/10.1016/j.atmosres.2019.104716

Hsieh, B.Z., Nghiem, L., Shen, C.H., Lin, Z.S., 2013. Effects of complex sandstone-shale sequences of a storage formation on the risk of $\mathrm{CO} 2$ leakage: Case study from Taiwan. Int. J. Greenh. Gas Control 17, 376-387. https://doi.org/10.1016/j.ijggc.2013.05.030

Iglauer, S., 2018. Optimum storage depths for structural CO2 trapping. Int. J. Greenh. Gas Control 77, 82-87. https://doi.org/10.1016/j.ijggc.2018.07.009

Issautier, B.Î., Fillacier, S., Le Gallo, Y., Audigane, P., Chiaberge, C., Viseur, S., 2013. Modelling of $\mathrm{CO} 2$ injection in fluvial sedimentary heterogeneous reservoirs to assess the impact of geological heterogeneities on CO2storage capacity and performance. Energy Procedia 37, 5181-5190. https://doi.org/10.1016/j.egypro.2013.06.434

Jia, W., McPherson, B., Pan, F., Dai, Z., Xiao, T., 2018. Uncertainty quantification of $\mathrm{CO} 2$ storage using Bayesian model averaging and polynomial chaos expansion. Int. J. Greenh. Gas Control 71, 104-115. https://doi.org/10.1016/j.ijggc.2018.02.015

Jin, M., Pickup, G., Mackay, E., Todd, A., Sohrabi, M., Monaghan, A., Naylor, M., 2012. Static and Dynamic Estimates of CO2-Storage Capacity in Two Saline Formations in the UK. SPE 
J. 17, 1108-1118. https://doi.org/10.2118/131609-PA

572 Jun, C., Kim, M., Shin, H., 2019. Optimization of well placement and operating conditions for

573 various well patterns in CO2 sequestration in the Pohang Basin, Korea. Int. J. Greenh. Gas

$574 \quad$ Control 90, 102810. https://doi.org/10.1016/j.ijggc.2019.102810

575 Khudaida, K.J., Das, D.B., 2020. A Numerical Analysis of the Effects of Supercritical CO2

576 Injection on CO2 Storage Capacities of Geological Formations. Clean Technol. 2, 333-364.

577 https://doi.org/10.3390/cleantechnol2030021

578 Kim, J., Song, Y., Shinn, Y., Kwon, Y., Jung, W., Sung, W., 2019. A study of CO2 storage

579 integrity with rate allocation in multi-layered aquifer. Geosci. J. 23, 823-832.

Kim, Y., Jang, H., Kim, J., Lee, J., 2017. Prediction of storage efficiency on CO 2 sequestration

Kumar, A., Ozah, R., Noh, M., Pope, G.A., Bryant, S., Sepehrnoori, K., Lake, L.W., 2005. Reservoir Simulation of CO2 Storage in Deep Saline Aquifers. SPE J. 10, 336-348. https://doi.org/10.2118/89343-PA

Lee, J.H., Park, Y.C., Sung, W.M., Lee, Y.S., 2010. A simulation of a trap mechanism for the sequestration of CO2 into gorae v aquifer, Korea. Energy Sources, Part A Recover. Util. Environ. Eff. 32, 796-808. https://doi.org/10.1080/15567030903436822

Li, Y.H., Shen, C.H., Wu, C.Y., Hsieh, B.Z., 2020. Numerical study of CO2 geological storage 590 in saline aquifers without the risk of leakage. Energies 13. https://doi.org/10.3390/en13205259

592 Liner, C.L., Geng, P., Zeng, J., King, H., Li, J., 2011. A CO2 Sequestration Simulation Case 593 Study at the Dickman Field, Ness Co ., Kansas, in: SPE Annual Technical Conference and 
Exhibition. Denver, Colorado, USA, pp. 1-15.

595

Liu, D., Li, Y., Agarwal, R., 2020. Evaluation of CO2 Storage in a Shale Gas Reservoir Compared to a Deep Saline Aquifer in the Ordos Basin of China. Energies 13.

Mahdaviara, M., Nait, M., Hemmati-sarapardeh, A., 2021. Toward smart schemes for modeling CO 2 solubility in crude oil : Application to carbon dioxide enhanced oil recovery. Fuel 285, 119147. https://doi.org/10.1016/j.fuel.2020.119147

Mohajeri, M., Shariatipour, S., 2019. Evaluation of enhancing CO2 sequestration by post-brine injection under different scenarios using the E300 compositional simulator. Pet. Res. 4, 314-333. https://doi.org/10.1016/j.ptlrs.2019.08.001

Nghiem, L, Shrivastava, V., Kohse, B., Hassam, M., Yang, C., 2009. Simulation of Trapping Processes for CO 2 Storage in Saline Aquifers.

Nghiem, Long, Yang, C., Shrivatava, V., Kohse, B., Hassam, M., Chen, D., Card, C., 2009. Optimization of Residual Gas and Solubility Trapping for CO 2 Storage in Saline Aquifers. Soc. Pet. Eng. 1-9. https://doi.org/10.1016/j.egypro.2009.02.079

Noushabadi, M.J., Training, T.I.F.P., Brisset, A., Thibeau, S., 2018. Investigation of CO2 Storage Security Increase by Brine Alternative CO2 Injection WAG_CCS, in: Abu Dhabi International Petroleum Exhibition \& Conference. Abu Dhabi, UAE, pp. 1-13.

Pedregosa, F., Weiss, R., Brucher, M., 2011. Scikit-learn : Machine Learning in Python. J. ofMachine Learn. Res. 12, 2825-2830.

Pham, V.T.H., Riis, F., Gjeldvik, I.T., Halland, E.K., Tappel, I.M., Aagaard, P., 2013. Assessment of CO2 injection into the south Utsira-Skade aquifer, the North Sea, Norway. Energy 55, 529-540. https://doi.org/10.1016/j.energy.2013.03.026

Sarkarfarshi, M., Malekzadeh, F.A., Gracie, R., Dusseault, M.B., 2014. Parametric sensitivity 
analysis for $\mathrm{CO} 2$ geosequestration. Int. J. Greenh. Gas Control 23, 61-71. https://doi.org/10.1016/j.ijggc.2014.02.003

Schmalensee, R., Stoker, T.M., Judson, R.A., 1998. World carbon dioxide emissions: 1950 2050. Rev. Econ. Stat. 80, 15-27. https://doi.org/https://doi.org/10.1162/003465398557294

Schölkopf, B., Smola, A.J., 2002. Learning with Kernels:Support Vector Machines, Regularization, Optimization, and Beyond. MIT Press.

Shin, Y., Kim, Taekgeun, Hong, Seoksu, Lee, S., Lee, E., Hong, Seungwoo, Lee, C., Kim, Taeyeon, Park, M.S., Park, J., Heo, T., n.d. Prediction of Chlorophyll- a Concentrations in the Nakdong River Using Machine Learning Methods.

Sifuentes, W., Blunt, M.J., Giddins, M. a., 2009. Modeling CO2 Storage in Aquifers : Assessing the Key Contributors to Uncertainty. SPE Offshore Eur. Oil Gas Conf. Exhib. SPE123582. https://doi.org/10.2118/123582-MS

Singh, M., Chaudhuri, A., Reza, M., Stauffer, P.H., 2021. Coupled multiphase flow and transport simulation to model $\mathrm{CO} 2$ dissolution and local capillary trapping in permeability and capillary heterogeneous reservoir. Int. J. Greenh. Gas Control 108. https://doi.org/10.1016/j.ijggc.2021.103329

Sohal, M.A., Le, Y., Audigane, P., Dios, J.C. De, Rigby, S.P., 2021. Effect of geological heterogeneities on reservoir storage capacity and migration of $\mathrm{CO} 2$ plume in a deep saline fractured carbonate aquifer. Int. J. Greenh. Gas Control 108.

Soltanian, M.R., Amooie, M.A., Cole, D.R., Graham, D.E., Hosseini, S.A., Hovorka, S., Pfiffner, S.M., Phelps, T.J., Moortgat, J., 2016. Simulating the Cranfield geological carbon sequestration project with high-resolution static models and an accurate equation of state. Int. J. Greenh. Gas Control 54, 282-296. https://doi.org/10.1016/j.ijggc.2016.10.002 
640 Song, Y., Sung, W., Jang, Y., Jung, W., 2020. Application of an artificial neural network in 641 predicting the effectiveness of trapping mechanisms on $\mathrm{CO} 2$ sequestration in saline aquifers. Int. J. Greenh. Gas Control 98, 103042. https://doi.org/10.1016/j.ijggc.2020.103042

Sung, R.T., Li, M.H., Dong, J.J., Lin, A.T.S., Hsu, S.K., Wang, C.Y., Yang, C.N., 2014. Numerical assessment of $\mathrm{CO} 2$ geological sequestration in sloping and layered heterogeneous formations: A case study from Taiwan. Int. J. Greenh. Gas Control 20, 168179. https://doi.org/10.1016/j.ijggc.2013.11.003

Sutton, C.D., 2005. Classification and Regression Trees, Bagging, and Boosting. Handb. ofStatistics 24, 303-329. https://doi.org/10.1016/S0169-7161(04)24011-1

Szulczewski, M.L., Macminn, C.W., Herzog, H.J., Juanes, R., 2012. Lifetime of carbon capture and storage as a climate-change mitigation technology. Proc. Natl. Acad. Sci. 109, 51855189. https://doi.org/10.1073/pnas.1115347109

Vapnik, V.N., 2013. The Nature of Statistical Learning Theory. Springer New York.

Vo Thanh, H., Sugai, Y., Nguele, R., Sasaki, K., 2020a. Robust optimization of CO2 sequestration through a water alternating gas process under geological uncertainties in Cuu Long Basin, Vietnam. J. Nat. Gas Sci. Eng. https://doi.org/10.1016/j.jngse.2020.103208

Vo Thanh, H., Sugai, Y., Nguele, R., Sasaki, K., 2020b. Robust optimization of CO2 sequestration through a water alternating gas process under geological uncertainties in Cuu Long Basin, Vietnam. J. Nat. Gas Sci. Eng. 76, 103208. https://doi.org/10.1016/j.jngse.2020.103208

Vo Thanh, H., Sugai, Y., Nguele, R., Sasaki, K., 2019. Integrated workflow in 3D geological model construction for evaluation of $\mathrm{CO} 2$ storage capacity of a fractured basement reservoir 
in Cuu Long Basin, Vietnam. Int. J. Greenh. Gas Control 90, 102826. https://doi.org/10.1016/j.ijggc.2019.102826

Vo Thanh, H., Sugai, Y., Sasaki, K., 2020c. Impact of a new geological modelling method on the enhancement of the $\mathrm{CO} 2$ storage assessment of E sequence of Nam Vang field, offshore Vietnam. Energy Sources, Part A Recover. Util. Environ. Eff. 42, 1499-1512. https://doi.org/10.1080/15567036.2019.1604865

Vo Thanh, H., Sugai, Y., Sasaki, K., 2020d. Application of artificial neural network for predicting the performance of $\mathrm{CO} 2$ enhanced oil recovery and storage in residual oil zones. Sci. Rep. 10, 18204. https://doi.org/10.1038/s41598-020-73931-2

Xiao, T., McPherson, B., Esser, R., Jia, W., Moodie, N., Chu, S., Lee, S.Y., 2019. Forecasting commercial-scale CO 2 storage capacity in deep saline reservoirs: Case study of Buzzard's bench, Central Utah. Comput. Geosci. 126, 41-51. https://doi.org/10.1016/j.cageo.2018.12.006

Xu, R., Zeng, K., Zhang, C., Jiang, P., 2017. Assessing the feasibility and CO2 storage capacity of $\mathrm{CO} 2$ enhanced shale gas recovery using Triple-Porosity reservoir model. Appl. Therm. Eng. 115, 1306-1314. https://doi.org/10.1016/j.applthermaleng.2017.01.062

Zapata, Y., Kristensen, M.R., Huerta, N., Brown, C., Kabir, C.S., Reza, Z., 2020. CO2 geological storage: Critical insights on plume dynamics and storage efficiency during longterm injection and post-injection periods. J. Nat. Gas Sci. Eng. 83, 103542. https://doi.org/10.1016/j.jngse.2020.103542

Zhang, D., Qian, L., Mao, B., Huang, C.A.N., Huang, B.I.N., 2018. A Data-Driven Design for Fault Detection of Wind Turbines Using Random Forests and XGboost. IEEE Access 6, 21020-21031. https://doi.org/10.1109/ACCESS.2018.2818678 
686 Zhang, J., Feng, Q., Zhang, X., Shu, C., Wang, S., Wu, K., 2020. A Supervised Learning 687 Approach for Accurate Modeling of CO 2 - Brine Interfacial Tension with Application in 688 Identifying the Optimum Sequestration Depth in Saline Aquifers. Energy \& Fuels 34, 7353689 7362. https://doi.org/10.1021/acs.energyfuels.0c00846

690 C.R. Goodall, Computation using the QR decomposition, Chapman Hall. Handb. Mod. Stat. 691 Methods 9 (1993) 467-508, https://doi.org/10.1016/S0169-7161(05) 80137-3.

692 A. Hemmati-Sarapardeh, F. Ameli, B. Dabir, M. Ahmadi, A.H. Mohammadi, On the evaluation 693 of asphaltene precipitation titration data: modeling and data assessment, Fluid Phase $694 \quad$ Equilib. 415 (2016) 88-100.

695 